\title{
FATTY ACIDS CONTENT IN UNGURAHUA OIL (OENOCARPUS BATAUA) FROM ECUADOR. FINDINGS ON ADULTERATION OF UNGURAHUA OIL IN ECUADOR
}

\author{
CARRILLO W*, CARPIO C, MORALES D, ÁLVAREZ M, SILVA M
}

Laboratory of Functional Foods, Faculty of Foods Science and Engineering, Technical University of Ambato, Av. Los Chasquis y Rio Payamino, Campus Huachi, CP 1801334, Ambato, Ecuador. Email: wi.carrillo@uta.edu.ec

Received:7 January 2017, Revised and Accepted:3 May 2017

\begin{abstract}
Objective: The aim of this study was to determine the fatty acids composition in an ungurahua seeds oil (Oenocarpus bataua) sample cultivated in Ecuador and to determine eventual adulteration in the composition of commercial ungurahua oil.
\end{abstract}

Methods: Oil was obtained from ungurahua seeds using the cold pressing method. Fatty acids analysis was performed using the gas chromatography (GC) method with a mass selective detector and using the database library NIST14.L to identify the compounds.

Results: Methyl esters fatty acids were identified from ungurahua (O. bataua) using the GC mass spectrometer analytical method. Ungurahua oil presented a high content of monounsaturated fatty acids with $82.03 \%$ of oleic acids. A fraud in the composition of fatty acids present in commercial ungurahua oil was found as fatty acids had a value of only $36.77 \%$ of oleic acids. The content of linoleic acid can be used to determine adulteration of this oil.

Conclusions: Ungurahua seeds are a good source of monounsaturated and fatty acids. The content of oleic acid is higher than in olive oil. Ungurahua can help reducing cardiovascular diseases risk in Ecuador due to its good composition of monounsaturated fatty acids. Ungurahua oil is a good option to be used in the food industry for different uses.

Keywords: Ungurahua oil, Oenocar pus bataua, Fatty acids, Lipids, Omega 9.

(c) 2018 The Authors. Published by Innovare Academic Sciences Pvt Ltd. This is an open access article under the CC BY license (http://creativecommons. org/licenses/by/4. 0/) DOI: http://dx.doi.org/10.22159/ajpcr.2018.v11i2.16967

\section{INTRODUCTION}

Oenocarpus bataua belongs to the Arecoideae subfamily, and it is a lesser-known palm tree. This fruit is named patawa, ungurahui, and ungurahua. Ungurahua is present throughout the Amazon and northern South America. The fruit pulp is not well characterized and could present an interesting nutritional value $[1,2]$. The mesocarp is eatable and nutritious, containing high-quality oil. Fruit pulp has a content of $29.1 \%$ fat, $7.4 \%$ of protein, and $44.7 \%$ fiber $[3,4]$. Amazonian fruits are rich in fat, but more than $61 \%$ of this fat is unsaturated and could be considered healthy fat, which can be used to cardiovascular risk prevention [5]. Monounsaturated fatty acids (MUFAs) are the predominant fatty acids in fruits and contribute, on average, approximately to $62 \%$ of the total fat. It is widely recognized that dietary fat type influences plasma cholesterol levels to a greater extent than does total fat intake [6]. Therefore, replacing saturated fat with unsaturated fat may be more effective in lowering the risk of coronary heart disease (CHD) than reducing fat intake [7]. Amazonian fruits also have high levels of tocopherols, which are present in the unsaponifiable lipid fraction of foods. Ungurahua oil profile is similar to the olive oil composition; ungurahua oil has a high content of oleic acid (omega 9) in similar proportions to the ones of the olive oil [8]. Frauds in various consumer sectors of the food industry are now commonly practiced in the world for a long time. This practice is increasing in developing countries. Vegetal oils are commonly adulterated with the addition of cheaper seeds oils [9-11]. Olive oil can be adulterated with soy oil, sunflower, and corn oil which are cheaper [12]. The analytical technique most used to determine this fraud is the chromatography and mass spectrometry (MS) $[13,14]$. The aim of this work was to identify the fatty acids composition present in ungurahua $(O$. bataua) seeds from Amazonia region of Ecuador using the gas chromatography MS
(GC-MS) and determine fraud in the composition of fatty acids from the commercial ungurahua oil of Ecuador.

\section{METHODS}

\section{Total lipid extraction}

Ungurahua oil was obtained in a regular supermarket in Ecuador. Ungurahua seeds were obtained in the Amazonia region. Oil sample was obtained from ungurahua seeds using the cold pressing method. Oil was then stored at $4.0 \pm 2^{\circ} \mathrm{C}$. Oil extraction was conducted using a Soxhlet apparatus for approximately $5 \mathrm{~h}$ with hexane as solvent, with a solid to solvent ratio of $1 / 7 \mathrm{~m} / \mathrm{v}$. After the extraction process, the flask contents were filtered, and the liquid fraction containing the lipid extract and solvent was poured into a $250-\mathrm{mL}$ flask of a rotary film evaporator to remove the solvent. The obtained oil was collected, evaporated under nitrogen, weighed, and stored in sealed amber glass vials at $-20^{\circ} \mathrm{C}$ until analysis [15].

\section{Fatty acid methyl esters (FAME)}

Methyl esters (FAME) were prepared with $0.020-0.025 \mathrm{~g}$ of total lipids of ungurahua oil using the two-step methylation method: $2 \mathrm{ml} 0.5 \mathrm{M}$ $\mathrm{KOH} / \mathrm{MeOH}$ was added and then $1 \mathrm{ml}$ of $5 \% \mathrm{HCl} / \mathrm{MeOH}$ was added; both steps were performed at $50^{\circ} \mathrm{C} .25$ min FAME were extracted with $10 \mathrm{ml}$ of hexane [16].

\section{Analysis of FAME from ungurahua by (GC-MS)}

The fatty acid composition of oil extracted from ungurahua seeds was analyzed by injecting FAME [17] into an Agilent technologies 7980A system GC (Agilent, Santa Clara, CA) equipped with a mass selective detector (MSD) 5977A GC, an autosampler 7693, column (60 $\mathrm{m} \times 250 \mu \mathrm{m} \times 0.25 \mu \mathrm{m}$, DB-WAX Agilent 122-7062). The oven 
temperature was programmed as follows: From $80^{\circ} \mathrm{C}$; ramp 1: To $100^{\circ} \mathrm{C}$ at $20^{\circ} \mathrm{C} / \mathrm{min}$ for $1 \mathrm{~min}$; ramp 2: At $200^{\circ} \mathrm{C}$ at $25^{\circ} \mathrm{C} / \mathrm{min}$ during $10 \mathrm{~min}$; and ramp 3: At $250^{\circ} \mathrm{C}$ at $2^{\circ} \mathrm{C} / \mathrm{min}$. The injector and detector temperatures were set at $250^{\circ} \mathrm{C}$. Helium was used as carrier gas at a linear flow velocity of $1.4 \mathrm{~mL} / \mathrm{min}$.

Spectra were compared with the NIST14.L library and the fatty acids mass spectra archive [18]. All GC analyses of fatty acids were carried out in triplicate, and results were expressed as the mean value \pm standard deviation.

\section{RESULTS}

Fig. 1 shows ungurahua seeds fruit (O. bataua) with or without skin. Fig. 1a shows the dark color of the whole ungurahua fruit and the inside fruit being of white color.

Ungurahua oil sample was obtained in the laboratory using the cold pressing method; fatty acids were subsequently methyl esterified. Fatty acids from ungurahua oils were identified using the GC/MSD. The precursor ions were compared to the three database Library NIST14. L. Five majority peaks were identified with their associated retention time: C16:0 with a retention time of $19.409 \mathrm{~min}$; C18:0 with a retention time of $26.095 \mathrm{~min}$; C18:1c with a retention time of $26.974 \mathrm{~min}$; C18:2 with a retention time of $28.974 \mathrm{~min}$; and finally, C18:3 with a retention time of 31.090 min (Fig. 2)

Fatty acids of commercial oil ungurahua from Ecuador were methyl esterified. Fatty acids from ungurahua oil were identified using the GC/MSD. The precursor ions were compared to three database library NIST14. L. Five majority peaks were identified with their associated retention time: C16:0 with a retention time of $19.354 \mathrm{~min}$; C18:0 with a retention time of $26.028 \mathrm{~min}$; C18:1c with a retention time of $26.891 \mathrm{~min}$; C18:2 with a retention time of $28.658 \mathrm{~min}$; and finally, C18:3 with a retention time of 31.21 min (Fig. 3).

The concentration of fatty acids in ungurahua oil obtained in the laboratory was calculated with a peak area percentage. FAMEs were characterized: C16:0 palmitic acid with $9.90 \%$ of fatty acids content, C18:0 stearic acid with $3.08 \%$ of fatty acids content, C18:1 oleic acid with $82.03 \%$ of fatty acids content, C18:2 linoleic acid with $1.60 \%$ of fatty acids content, and finally C18:3 linolenic acid with $1.82 \%$ of fatty acids content (Table 1). The content of oleic acid (omega 9) was very high. The content of oleic acid in olive oil is reported to have a value between $62 \%$ and $80 \%$ of oleic acid. The content of oleic acid from ungurahua oil was higher with a value of $82.03 \%$ of oleic acid. The content of monounsaturated lipids was very high. Our results are in accordance with values reported by other authors. Darnet et al., 2011 [3], reported the composition of fatty acids of 0 . bataua from the Brazilian Amazonia with values of $13.5 \%$ of palmitic acid, $4.2 \%$ of stearic acid, $76.8 \%$ of oleic acid, $3.9 \%$ of linoleic acid, and $0.0 \%$ of linolenic acid. Rodrigues et al., 2010 [4], also have reported the content of fatty acids of 0 . bataua from the Brazilian Amazonia with values of $13.30 \%$ of palmitic acid, $4.10 \%$ of stearic acid, $76.70 \%$ of oleic acid, $3.90 \%$ of linoleic acid, and $0.10 \%$ of linolenic acid.

The concentration of fatty acids in commercial ungurahua oil obtained in a regular supermarket in Ecuador was calculated using the peak area percentage. FAMEs were characterized: C16:0 palmitic acid with $19.47 \%$ of fatty content, C18:0 stearic acid with $5.11 \%$ of fatty content, C18:1 oleic acid with $36.77 \%$ of fatty content, C18:2 linoleic acid with $35.78 \%$ of fatty content, and finally C18:3 linolenic acid with $2.86 \%$ of fatty content (Table 2). The profile of ungurahua oil is different to the commercial ungurahua oil when compared to the ungurahua oil obtained in the laboratory. The oleic acid is much lower with a value of only $36.77 \%$ while the linoleic acid is higher with a value of $35.78 \%$.

\section{DISCUSSION}

When the ungurahua fatty acids composition is compared to some other common vegetable oils, it can be seen that olive oil has a high content of monounsaturated fatty acids and C18:1 named oleic acid with $77.6 \%$ of oleic acid. Ungurahua oil from Ecuador has a higher content of monounsaturated fatty acids with a content of $82.03 \%$ of oleic acid. Ungurahua has a low content of polyunsaturated fatty acids

Table 1: Content of fatty acids of ungurahua oil obtained in the laboratory

\begin{tabular}{|c|c|c|c|c|}
\hline Retention time & Peak area ratio $(\%)$ & Carbone number: double bound & Type of fatty acids & FAMEs name \\
\hline $19.409 \mathrm{~min}$ & $9.900 \pm 0.182$ & C16:0 & Saturated & Palmitic acid \\
\hline $26.095 \mathrm{~min}$ & $3.084 \pm 0.140$ & C18:0 & Saturated & Stearic acid \\
\hline $26.974 \mathrm{~min}$ & $82.032 \pm 1.630$ & $\Delta 9 \mathrm{C} 18: 1$ & Monounsaturated & Oleic acid \\
\hline $28.717 \mathrm{~min}$ & $1.603 \pm 0.483$ & $\Delta 9.12 \mathrm{C} 18: 2$ & Polyunsaturated & Linoleic acid \\
\hline $31.090 \mathrm{~min}$ & $1.823 \pm 2.454$ & $\Delta 9.12 .15 \mathrm{C} 18: 3$ & Polyunsaturated & Linolenic acid \\
\hline
\end{tabular}

FAMEs: Fatty acid methyl esters

Table 2: Content of fatty acids of commercial ungurahua oil

\begin{tabular}{lllll}
\hline Retention time & Peak area ratio (\%) & Carbone number: double bound & Type of fatty acids & FAMEs name \\
\hline $19.354 \mathrm{~min}$ & $19.470 \pm 0.142$ & $\mathrm{C} 16: 0$ & Saturated & Palmitic acid \\
$26.028 \mathrm{~min}$ & $5.110 \pm 0.115$ & C18:0 & Saturated & Stearic acid \\
$26.891 \mathrm{~min}$ & $36.775 \pm 0.730$ & $\Delta 9 \mathrm{C} 18: 1$ & Monounsaturated & Oleic acid \\
$28.658 \mathrm{~min}$ & $35.780 \pm 0.283$ & $\Delta 9.12 \mathrm{C} 18: 2$ & Polyunsaturated & Linoleic acid \\
$31.121 \mathrm{~min}$ & $2.863 \pm 0.826$ & $\Delta 9.12 .15 \mathrm{C} 18: 3$ & Polyunsaturated & Linolenic acid \\
\hline
\end{tabular}

FAMEs: Fatty acid methyl esters

Table 3: Content of fatty acid of common vegetal oils

\begin{tabular}{llllllll}
\hline Ref & Vegetal oil & C16:0 & C16:1 & C18:0 & C18:1 & C18:2 & C18:3 \\
\hline 25 & Olive oil & 13.8 & 1.4 & 2.8 & 71.6 & 9.00 & 1.0 \\
25 & Sunflower oil & 5.2 & 0.1 & 3.7 & 33.7 & 56.5 & 0.0 \\
25 & Palm oil & 44.8 & 0.0 & 4.6 & 38.9 & 5.5 & 0.4 \\
25 & Soybean oil & 10.1 & 0.0 & 4.3 & 22.3 & 4.7 & 1.4 \\
25 & Corn oil & 11.6 & 0.0 & 2.5 & 38.7 & 34.98 & 47.04 \\
26 & Sacha inchi oil & 3.98 & 0.0 & 3.12 & 8.58 & 3.98 & 0.0 \\
27 & Sambo oil & 9.33 & 0.0 & 6.84 & 41.36 & 1.60 & 1.82 \\
\hline & Ungurahua oil & 9.90 & 0.0 & 3.08 & 82.03 & &
\end{tabular}


with $3.426 \%$. Olive oil contains few omega- 6 and omega-3 fatty acids with $9.0 \%$ and $1.0 \%$, respectively (Table 3).

The content of linoleic acid can be used to determine fraud in vegetal oils. Christopoulou et al., 2004, reported that linolenic acid (C18:3) can be used to determinate fraud in olive oil when mixed with other oils such as soybean oil and sunflower oil [19]. In this study, we used linoleic acid to determine fraud in ungurahua oil because the content of linoleic acid was high. Sunflower and soybean oils both have a high content of linoleic acid (Table 3). It is possible that fraud in ungurahua oil was committed using any of these vegetal oils. Vegetal oils with high quality in their composition of lipids are susceptible of adulteration. Olive oil is one of the oils with more adulteration in the past; this situation affects a high number of foods which have olive oil in their composition resulting in high economic losses in the food industry. Techniques such as high

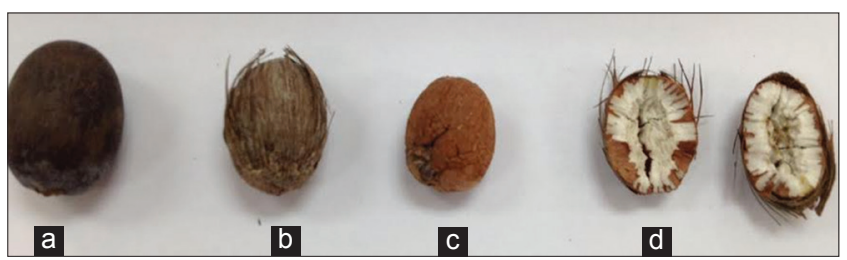

Fig. 1: Fruit of ungurahua (Oenocarpus bataua) (a) whole fruit, (b) fruit without skin, (c) fruit without fiber, and (d) pulp fruit pressure liquid chromatography, GC, near infrared, and RMN are used to identify adulterants present in vegetal oils $[20,21]$.

Food is an important element for human life and for social and economic prosperity and progress. Problems related to food have a big varied during different historic times, from continent to continent, and from country to country and cities [22]. The problem of foodstuff adulteration has been a major one, and the protection of the consumer has occupied the attention of many governments for a long time. Food authentication is an important aspect of food quality control in the food industry. Foodstuff is considered adulterated if it contains poisons or other substances which can be dangerous to the health of the consumers, if it contains impurities; if it contains a chemical components such as coloring agent or other food additive, that is not approved or contains materials that produce inferior quality; if any important constituent has been wholly or in part abstracted or any specified ingredient has been changing by other ingredients without the specified ingredient; if it contains any component that alters its weight and bulk or changes its strength to improve appearance. A food is mislabeling if it is illicitly labeled or it is a food for which standards of identity have been written, and it fails to comply with these standards $[23,24]$. The detection of adulteration of foodstuff is a technical problem that is needed to solve with many quality control for the government and with good norms of control.

Oleic acid is recommended for food and drug administration (FDA) as an intake of MUFAs to reduce the risk of cardiovascular diseases in the

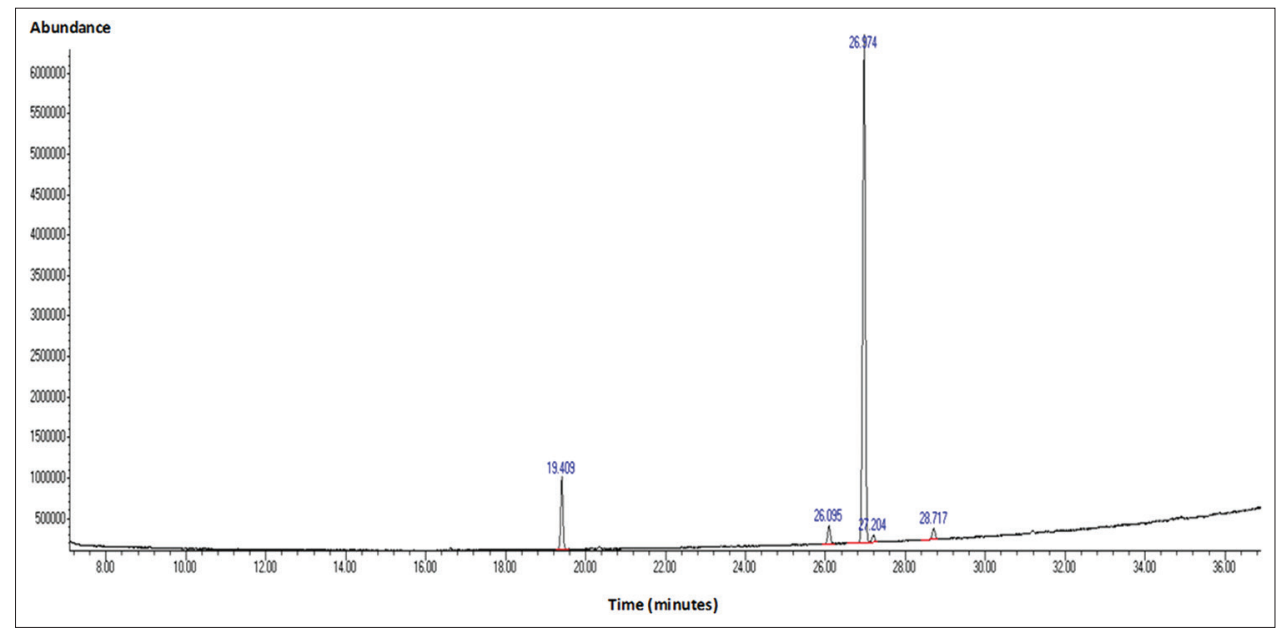

Fig. 2: Chromatography gases analysis of ungurahua oil obtained in the laboratory

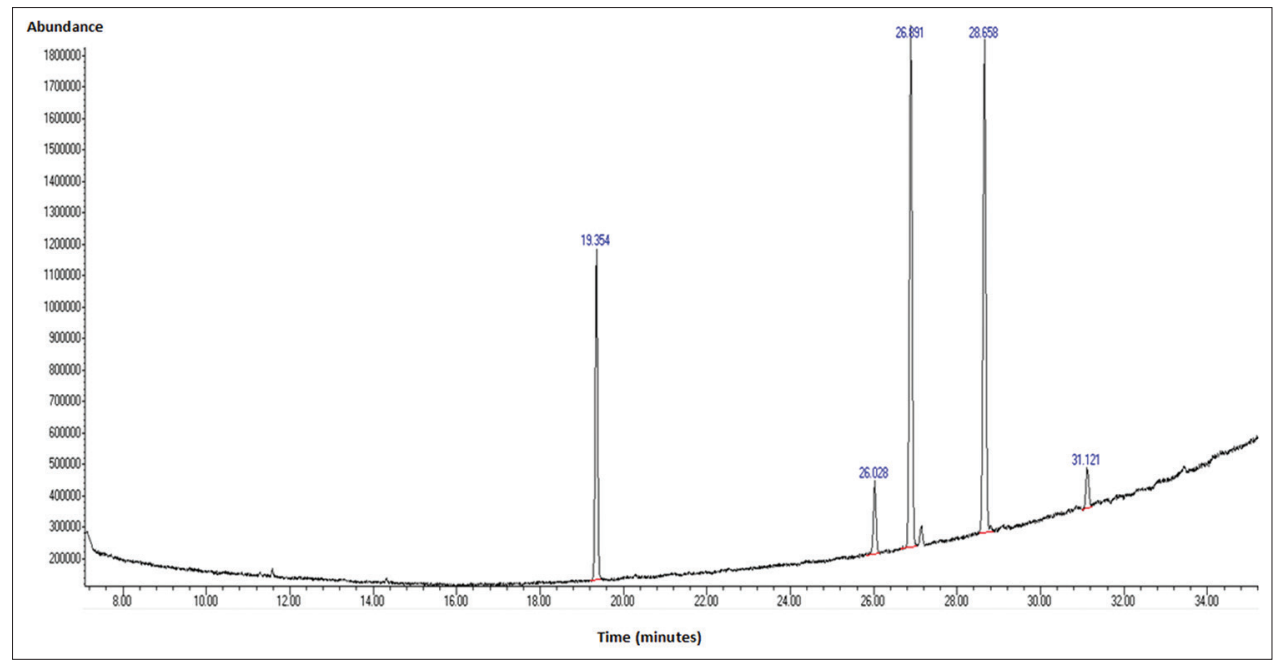

Fig. 3: Chromatography gases analysis of commercial ungurahua oil from ecuador 
world. In 2004, the FDA authorized a health claim on olive oil on CHD: "Limited and not conclusive scientific evidence suggests that eating about two tablespoons ( $23 \mathrm{~g}$ ) of olive oil daily may reduce the risk of CHD due to the monounsaturated fat in olive oil. To achieve this possible benefit, olive oil is to replace a similar amount of saturated fat and not increase the total number of calories you eat in a day" [28]. A recent study from the European food safety authority supports the effects of virgin olive oil phenols on low-density lipoproteins (LDL) oxidation [29]. Extra virgin olive oil contains MUFA (oleic acid) and phenols compounds with antioxidant capacity. It is well known that oxidation of LDL cholesterol is a key important factor in the development of atherosclerosis, promoting the formation of foam cells in the subendothelial space of the vascular wall. Oleic acid and phenols help avoiding this oxidation when taking in the daily human diet. It is estimated that by the year 2050 over 1.5 billion people are hypertension disease. It is known that diabetes mellitus Type 2 can cause cardiovascular risk. The cardiovascular disease caused the highest mortality in 2012 including 7.4 million for CHD and 6.7 million for stroke [30,31]. Ungurahua oil has a good composition of fatty acids with a high content of MUFAs (oleic acid omega 9). This oil can be help preventing the cardiovascular risks and reducing cholesterol. Ungurahua oil due to its composition of fatty acids can be considered as a healthy oil.

\section{CONCLUSION}

Ungurahua oil (O. bataua) presents a high content of monounsaturated fatty oil with a value of $82.03 \%$ of oleic acid. Ungurahua oil content low palmitic and stearic acid with a value of $9.90 \%$ and $3.08 \%$, respectively. Ungurahua oil has a good composition of fatty acid and for their high content of oleic acid can be consumed to the prevention of cardiovascular risk. Commercial ungurahua oil presents adulteration in its composition of fatty acid.

\section{ACKNOWLEDGMENTS}

This study was supported by Universidad Técnica de Ambato, Ecuador (ProjectCPU-1373-2014-UTA) and (ProjectCanje de DeudaEspaña-Ecuador). This work has been reviewed in the English edition by Emilio Labrador.

\section{AUTHOR'S CONTRIBUTIONS}

Carrillo W, Carpio C, and Morales D conceived and designed the experiments. Silva M and Alvarez M performed the GC analyses. Carrillo $\mathrm{W}$ wrote the paper.

\section{CONFLICT OF INTERESTS}

The authors declare no conflict of interest.

\section{REFERENCES}

1. Montúfar R, Laffargue A, Pintaud JC, Hamon S, Avallone S, Dussert S. Oenocarpus bataua Mart.(Arecaceae): Rediscovering a source of high oleic vegetable oil from Amazonia. J Am Oil Chem Soc 200;87;167-72.

2. Miller C. Fruit production of the ungurahua palm (Oenocarpus bataua subsp. Bataua, Arecaceae) in an indigenous managed reserve. Econ Bot 2002;56:165-76.

3. Darnet SH, Silva LH, Rodrigues AM, Lins RT. Nutritional composition, fatty acid and tocopherol contents of buriti (Mauritia flexuosa) and patawa (Oenocarpus bataua) fruit pulp from the Amazon region. Food Sci Technol Camp 2011;31:488-91.

4. Rodrigues AM, Darnet S, Silva LH. Fatty acid profiles and tocopherol contents of buriti (Mauritia flexuosa), patawa (Oenocarpus bataua), tucuma (Astrocaryum vulgare), mari (Poraqueiba paraensis) and inaja (Maximilian amaripa) fruits. J Braz Chem Soc 2010;21:2000-4.

5. Rezaire A, Robinson JC, Bereau D, Verbaere A, Sommerer N, Khan MK, et al. Amazonian palm Oenocarpus bataua ("patawa"): Chemical and biological antioxidant activity phytochemical composition. Food Chem 2014;149:62-70.

6. Brigelius-Flohé R, Traber MG. Vitamin E: Function and metabolism. FASEB J 1999;13:1145-55.

7. Simopoulos AP. New products from the agri-food industry: The return of n-3 fatty acids into the food supply. Lipids 1999;34 Suppl: S297-301.

8. Mambrin MC, Arellano DB. Characterization of palm tree fruit oils from Brazilian Amazonia region. Grasas Aceites 1997;48:154-8.
9. Cordella C, Moussa I, Martel AC, Sbirrazzuoli N, Lizzani-Cuvelier L. Recent developments in food characterization and adulteration detection: Technique-oriented perspectives. J Agric Food Chem 2002;50:1751-64.

10. del Castillo ML, Caja MM, Herraiz M, Blanch GP. Rapid recognition of olive oil adulterated with hazelnut oil by direct analysis of the enantiomeric composition of filberstone. J Agric Food Chem 1998;46:5128-31.

11. Georgouli K, Martinez Del Rincon J, Koidis A. Continuous statistical modelling for rapid detection of adulteration of extra virgin olive oil using mid infrared and Raman spectroscopic data. Food Chem 2017;217:735-42.

12. Van Durme J, Vandamme J. Non-thermal plasma as preparative technique to evaluate olive oil adulteration. Food Chem 2016;208:185-91.

13. Jabeur H, Zribi A, Bouaziz M. Extra-virgin olive oil and cheap vegetable oils: Distinction and detection of adulteration as determined by GC and chemometrics. Food Anal Met 2016;9:712-23.

14. Zribi A, Jabeur H, Aladedunye F, Rebai A, Matthäus B, Bouaziz M. Monitoring of quality and stability characteristics and fatty acid compositions of refined olive and seed oils during repeated pan-and deep-frying using GC, FT-NIRS, and chemometrics. J Agric Food Chem 2014;62:10357-67.

15. Stevenson DG, Eller FJ, Wang L, Jane JL, Wang T, Inglett GE. Oil and tocopherol content and composition of pumpkin seed oil in 12 cultivars. J Agric Food Chem 2007;55:4005-13.

16. Gutiérrez LF, Rosada LM, Jiménez A. Chemical composition of sacha inchi (Plukenetia volubilis L.) seeds and characteristics of their lipid fraction. Grasas Aceites 2011;62:76-83.

17. House SD, Larson PA, Johnson RR, De Vries JW, Martin DL. Gas chromatographic determination of total fat extracted from food samples using hydrolysis in the presence of antioxidant. J Assoc Off Anal Chem 1994;77:960-5.

18. Christie WW. Mass Spectrometry of Fatty Acid Derivatives; 2014. Available from: http://www.lipidlibrary.aocs.org/ms/masspec.html. [Last accessed on 2014 Mar 20].

19. Christopoulou E, Lazaraki M, Komaitis M, Kaselimis K. Effectiveness of determinations of fatty acids and triglycerides forthe detection of adulteration of olive oils with vegetable oils. Food Chem 2004;84:463- 74

20. Jiménez-Carvelo AM, González-Casado A, Cuadros-Rodríguez L. A new analytical method for quantification of olive and palm oil in blends with other vegetable edible oils based on the chromatographic fingerprints from the methyl-transesterified fraction. Talanta 2017;164:540-7.

21. Ruiz-Samblás C, Marini F, Cuadros-Rodríguez L, González-Casado A. Quantification of blending of olive oils and edible vegetable oils by triacyglycerol finger print gas chromatography and chemometric tools. J Chromat B 2012;910:71-7.

22. Manning L, Soon JM. Developing systems to control food adulteration. Food Policy 2014;49:23-32.

23. Rossell JB, King B, Downes MJ. Detection of adulteration. J Am Oil Chem Soc 1983;60:333-9.

24. Marikkar JN, Mirghani ME, Jaswir I. Application of chromatographic and infra-red spectroscopic techniques for detection of adulteration in food lipids: A review. J Food Chem Nanotechnol 2016;2:32-41.

25. Kamal-Eldin A, Andersson R. A multivariate study of the correlation between tocopherol content and fatty acid composition in vegetable oils. J Am Oil Chem Soc 1997;4:375-80.

26. Quinteros MF, Carpio C, Morales D, Vasquez G, Alvarez M, Silva M, et al. Identification of fatty acids in sachainchi oil (Plukenetia volubilis L.) from Ecuador. Asian J Pharm Clin Res 2017

27. Carrillo C, Carpio C, Morales D, Vilcacundo E, Alvarez M, Silva $\mathrm{M}$, et al. Characterization of fatty acids in sambo oil (Cucurbita ficifolia L.) from Ecuador. Asian J Pharm Clin Res 2017;10:303-6.

28. FDA. Monounsaturated Fatty Acids from Olive Oil and Coronary Heartdisease - Health Claim Petition Docket No. 2003Q-0559. Vol. 2003Q-0559. Rome, Italy: FDA; 2004.

29. EFSA. Panel on dietetic products, nutrition and allergies (NDA). Scientific opinion on the substantiation of health claims related to polyphenols in olive and protection of LDL particles from oxidative damage (ID 1333, 1638, 1639, 1696, 2865) pursuant to article 13(1) of regulation (EC) No 1924/2006. EFSA Journal 2011;9:2033.

30. Suhadi R, Thobari J, Irawan B, Dwiprahasto I. The blood pressure and therapy expenditure change due to hypertension comorbidity: An analytical prospective study in secondary care hospitals in Jogjakarta Indonesia. Int J Pharm Pharm Sci 2016;8:78-83.

31. Tolba M, Khashab K, Said A. The effect of dipeptidyl peptidase-4 inhibitors on cardiovascular disease risk in Type 2 diabetes mellitus. Int J Pharm Pharm Sci 2016;9:254-9. 